\title{
Research on the Dominant Knowledge Field of Independent Innovation in Manufacturing Enterprises
}

\author{
Gang Li \\ Hubei Communications Technical College, Wuhan, Hubei Province, China \\ 761615801@qq.com
}

\begin{abstract}
Keywords: Dominant knowledge; Knowledge field; Independent innovation; Manufacturing enterprises
\end{abstract}

\begin{abstract}
This paper summarizes the research direction and current status of teachers in colleges and universities in recent years in the field of human resources, found mainly in three aspects: teachers of university human resource allocation, management, development, the establishment of incentive mechanism and risk analysis; definition, value, value of human capital property rights of university teachers; teachers in colleges and universities human resource value measurement and the distribution of income, personal income and cost of investment in higher education. On this basis, this paper analyzes the existing problems in the research of human resource input and output efficiency of university teachers, and puts forward that the future research direction should focus on the comparison of college Teachers' professional superiority.
\end{abstract}

\section{Introduction}

The response of manufacturing enterprises to innovation policies is to influence or improve the speed, direction and scale of enterprises' independent innovation. As an important indicator of policies and measures to promote independent innovation activities and standardize independent innovation behavior, the response sensitivity of the policy orientation of manufacturing enterprises not only involves financial and financial policies and resource allocation policies of independent innovation activities, but also covers social development policies, talents and employment policies and so on. The speed and accuracy of policy formulation and adjustment fully reflect the sensitivity of manufacturing enterprises to the innovation policies formulated by the government. Through the introduction and implementation of policy introduction and implementation to promote the efficiency of independent innovation of enterprises, create a good innovation environment for enterprises, and further promote the creation, utilization and diffusion of innovation.

\section{Independent Innovation of Dominant Knowledge Elements}

Policy information. Policy information refers to the information knowledge issued by the government, which involves the development direction, positioning of the manufacturing enterprises, and the development policies and plans related to the independent innovation of the manufacturing enterprises, as well as related tax, investment, and government purchase. Only when we understand and grasp government policies in a timely manner can we make flexible use of policies and make quick decisions. With the continuous accumulation of independent innovation knowledge in manufacturing enterprises, the enterprise R \& D personnel more and more realize that the government policy has started the process of independent innovation of Jiangxi manufacturing industry, which is not limited to the general guidance, but through the forward pull, backward promotion, horizontal participation and vertical support to encourage the enterprise to carry out independent innovation.

Related laws and regulations. As an important component of the national superstructure, laws and regulations can play an important role in ensuring and adjusting the state's independent innovation activities. The degree of familiarity of relevant laws and regulations refers to the degree of understanding, mastering and applying the enterprises' laws and regulations to the enterprises, such as the current 
effective economic laws, administrative regulations, judicial interpretations, departmental rules and other normative documents. Through the continuous improvement and implementation of laws and regulations on intellectual property, competition laws and regulations, environment and energy standards, the state can create a suitable technological, economic and social environment for the start, organization and Realization of technological innovation, thus promoting the healthy and rapid development of innovation practice.

The manufacturing enterprises are familiar with the laws and regulations related to independent innovation. On the one hand, the intellectual property of the innovative products can be guaranteed not to be infringed and the interests of the R \& D investment of the enterprises are guaranteed. On the other hand, the uncertainty and externality in the R \& D process and the waste of innovation resources caused by the market failure are solved by the corresponding laws and regulations. A series of problems. As an important part of superstructure, laws and regulations play an important role in ensuring and adjusting the independent innovation activities of manufacturing enterprises. By constantly mastering and utilizing the laws and regulations in the field of competition and the laws and regulations on intellectual property, the manufacturing enterprises make the products produced to meet the standards of the environment and energy, and lay a solid foundation for the successful implementation of independent innovation, organization and Realization of a suitable technical, economic and social environment for the enterprise. The foundation of this system has promoted the steady and rapid development of enterprises' independent innovation practice.

Knowledge matching. Knowledge matching refers to the matching status of new products, new production methods, new markets or new supply sources of raw materials or semi-finished products, which are acquired through interaction with the external environment.

In the dynamic system of enterprise independent innovation, the matching relationship between knowledge and innovative resources determines the degree of realization of the value of new products and processes. Good knowledge can not only shorten the time of independent innovation, but also reduce the risk and cost of innovation. Knowledge matching is one of the key links in derivation of independent innovation. To explore the specific independent innovation problem, manufacturing enterprises depend not only on the theoretical knowledge under specific circumstances, but also on the degree of knowledge and the matching of innovative knowledge related to the independent innovation behavior of the enterprises.

From the perspective of knowledge management, knowledge matching reflects the performance level of independent innovation, and reflects the competitiveness of manufacturing enterprises from the perspective of enterprise competition. The higher the degree of correlation between knowledge support and independent innovation of manufacturing enterprises, the higher the success rate of independent innovation. Knowledge matching can also be regarded as a test and evaluation of the effectiveness of enterprise independent innovation. Compared with the benefit of manufacturing enterprises, the knowledge of enterprises has provided the attribute factors to meet the needs of enterprise innovation in a wide range and in a deep degree by analyzing the independent innovation of enterprises for a period of time.

Market demand information. Market demand information refers to the existing demand in the product market or technology market and a demand orientation for the future. The information of market demand information, as the knowledge element of the independent innovation knowledge system of manufacturing enterprises, is mainly reflected in driving the enterprise to carry out independent innovation. That is, it induces the enterprise to make the independent innovation strategy in advance through the demand knowledge orientation of the enterprise, so as to stimulate the enterprise to carry out independent innovation. Driven by the demand knowledge oriented, enterprises rely on knowledge to make independent innovation decisions, which make the cost curve move downward and produce excess profits, thus making innovation sustainable.

Market demand information is the basic starting point for manufacturing enterprises to make independent innovation decisions, as well as the main power source of independent innovation activities. It transfers the consumer's demand information to the manufacturing enterprises, and then makes the enterprise obtain the goal pointing and idea of independent innovation, and stimulate the driving force of 
independent innovation of the manufacturing enterprises. Demand knowledge is the satisfaction of the consumer to the price, utility, variety and quantity of the product or service. The purpose of the enterprise's independent innovation is to obtain excess profit and improve the competitiveness of the enterprise in an all-round way. The specific embodiment is to change the cost and quality of the product and service. The implementation of independent innovation of enterprises is closely related.

Knowledge Differentiation. Knowledge differentiation means that in the process of independent innovation, by applying the unique knowledge owned by the enterprise to the independent innovation, it can distinguish the innovation results from the other competitive enterprises effectively, so as to make the enterprise occupy a favorable position in the market competition. The greater the degree of knowledge differentiation between enterprises, the less likely their innovation will be imitated, and the greater the probability of independent innovation success.

In the competitive environment of the market, the products produced and sold by many enterprises are often the same. Customers choose the most suitable products according to their own preferences and perception of their products and their services. At this time, knowledge differentiation in the independent innovation of manufacturing enterprises makes it difficult for the enterprises to imitate the competitors. It also brings high satisfaction to the customers, and makes the products and services of independent innovation unimpeded in the market, and ensures the sustainability and effectiveness of independent innovation of manufacturing enterprises. In essence, knowledge differentiation is embodied in the value perceived by its customers, rather than the evaluation made by manufacturing enterprises themselves.

Information Technology. Information technology is one of the main achievements of enterprises in information technology, and it is the application of information technology in production, operation and management of enterprises. The rapid development of information technology speeds up the flow of knowledge between enterprises and enterprises. Through the diffusion of knowledge, we will apply innovative results to other markets, increase market share and increase the rate of return on investment. Through knowledge inflow, we can quickly acquire external knowledge and technology, integrate with the original knowledge of enterprises, and enhance the knowledge advantage of enterprises' independent innovation.

The popularity of information technology in manufacturing enterprises is embodied in the wide application of electronic information technology. The manufacturing enterprises with high popularity of information technology can realize automation of production design, automation control and so on, and reduce the complexity of the knowledge that the employees need to master. Through the application of information technology, the data of production, sales and finance are processed, and the data of enterprises are automated and information-based to realize the collection, storage, processing, transmission, analysis and utilization of the information of independent innovation activities of the enterprises, and provide a new decision basis for the manufacturing enterprises.

Knowledge Potential Energy. Knowledge potential energy refers to the state of knowledge level that a company has in a certain period of time relative to a reference individual, that is, the level of knowledge stock. Knowledge potential difference is the difference of knowledge potential between different enterprises at the same time relative to the same reference frame. Because the distribution of innovative knowledge resources is uneven among different enterprises, there is imbalance. The unbalanced distribution of knowledge resources is the main reason for the poor knowledge potential among enterprises.

It is precisely because of the existence of knowledge potential that leads to the transfer, flow and dissemination of innovation resources within and between enterprises. Generally speaking, innovative knowledge is always transferred from an enterprise with high knowledge potential to an enterprise with low knowledge potential. The improvement of the capability of independent innovation in Jiangxi's manufacturing industry is the result of accumulation of knowledge potential energy and the formation and improvement of knowledge potential energy. The greater the distribution density of innovation knowledge resources in manufacturing enterprises, the greater the accumulated knowledge stock, the 
stronger the competitiveness of the market and the higher economic benefits, resulting in the stronger demand for innovative knowledge resources in the manufacturing enterprises.

\section{The Role of Dominant Knowledge Elements}

In the rapid development of the information economy, the market is the foundation of the survival and development of the enterprise. The production and operation of the enterprise must be carried out according to the market, and the knowledge of the enterprise's knowledge of the market demand is the key to deciding whether the enterprise should carry on the independent innovation and carry on the independent innovation. Demand is the basic driving force for the independent innovation of Jiangxi manufacturing enterprises, and is the fundamental starting point. Enterprises' independent innovation according to the market demand is a guarantee for the enterprise's innovation income, which improves the initiative of innovation and reduces the blindness of innovation. Therefore, in the process of independent innovation of manufacturing enterprises in Jiangxi, demand knowledge orientation is a key link in knowledge creation and acquisition. Whether the enterprise wants to make independent innovation is decided by the demand of the market. When a new demand appears in the market, or the existing product supply is beyond the demand, it is unable to meet the increasing consumer demand. In order to occupy the potential market vacancy quickly, the enterprise can seize the market opportunity and gain more. On the other hand, the research and development of more advanced products or new products will be carried out to promote the independent innovation of the enterprises. On the other hand, if the market demand of the existing products is unsaturated and supply is less than demand, the enterprises will still be able to gain profit by continuing to produce existing products, and enterprises will not be eager to carry out independent innovation.

When a product of an enterprise is brought to the market and a good market effect has been achieved, many enterprises often follow their own products to produce the products, making the products in the market poor, which will affect the market share of the products. Therefore, under the premise of full knowledge creation and acquisition, enterprises should carry out independent innovation, improve the degree of knowledge differentiation of the products, distinguish the similar products from other enterprises, and occupy the leading position in the market competition. In the information age, information is the key to enterprise competition. The popularity of information technology is the driving force for the independent innovation of Jiangxi manufacturing enterprises. Therefore, the manufacturing enterprises in Jiangxi should fully acquire knowledge and actively study information technology so that they can be fully utilized in the production, management and management of the enterprises. It provides the basis for the independent innovation of the enterprise. The world is changing rapidly, every moment has new knowledge. Enterprises should acquire new knowledge in the market in time, understand the basic research, application research, development and research trends of related products, capture the knowledge signals that can be produced and commercialized in different research links in time, and provide independent innovation for enterprises.

To survive in the market environment, enterprises have to face all kinds of competition, and the enterprises with strong competitive ability have high knowledge potential in the competition. Then these enterprises can effectively concentrate the resources in the market. These enterprises will give priority to the development, so other enterprises can occupy a place in the competition. Raising their knowledge potential and concentrating resources will lead to independent innovation activities. In order to carry out independent innovation, enterprises will create knowledge on the basis of existing products, continue to absorb the popular elements in the industry, acquire new knowledge, fill the original products, make the enterprises innovate on the basis of existing products, and produce products with higher knowledge differentiation range, thus occupying the central city. The field. The response sensitivity of enterprises to policy orientation plays an important role in motivating the independent innovation of Jiangxi manufacturing enterprises. If the enterprise can not respond to the policy of government policy in time and the policies of tax, investment and subsidy, the enterprise may miss the good opportunity for the government to support the independent innovation of the enterprise, and affect the successful start-up and capital guarantee of the independent innovation of the enterprise. 


\section{References}

[1] Breschi, S. The Geography on innovation. A cross-sector analysis, 2010 (6):213-229.

[2] J. Chen, W.G. Qu. A new technological learning in China. Technovation, 2013(23):861-867.

[3] Dodgson, M. And J. Besant. Effective Innovation Policy. London, International Thomson Business Press, 2011, 56-69.

[4] Peng L, Fang W. Heterogeneity of Inferring Reputation of Cooperative Behaviors for the Prisoners' Dilemma Game [J]. Physica A: Statistical Mechanics and its Applications, 2015, 433: 367-378. 